\title{
Identification of genetic factors controlling kernel hardness and related traits in a recombinant inbred population derived from a soft $x$ 'extra-soft' wheat (Triticum aestivum $L$.) cross
}

\author{
Guomei Wang • Jeffrey M. Leonard • Andrew S. Ross • \\ C. James Peterson • Robert S. Zemetra • \\ Kimberly Garland Campbell · Oscar Riera-Lizarazu
}

Received: 28 May 2011/Accepted: 29 August 2011/Published online: 30 September 2011

(C) Springer-Verlag 2011

\begin{abstract}
Kernel hardness or texture, used to classify wheat (Triticum aestivum L.) into soft and hard classes, is a major determinant of milling and baking quality. Wheat genotypes in the soft class that are termed 'extra-soft' (with kernel hardness in the lower end of the spectrum) have been associated with superior end-use quality. In order to better understand the relationship between kernel hardness, milling yield, and various agronomic traits, we performed
\end{abstract}

Communicated by Y. Xu.

Electronic supplementary material The online version of this article (doi:10.1007/s00122-011-1699-0) contains supplementary material, which is available to authorized users.

G. Wang $(\bowtie) \cdot$ J. M. Leonard · A. S. Ross ·

C. J. Peterson · O. Riera-Lizarazu

Department of Crop and Soil Science, Oregon State University, 107 Crop Science Building, Corvallis, OR 97331-3002, USA

e-mail: Guomei.Wang@ oregonstate.edu

R. S. Zemetra

Department of Plant, Soil, and Entomological Sciences,

University of Idaho, Ag Science 319A, Moscow,

ID 83844-2339, USA

K. Garland Campbell

Department of Crop and Soil Sciences, Washington State

University, Pullman, WA 99164-6420, USA

K. Garland Campbell

US Department of Agriculture, Agricultural Research Service, Wheat Genetics, Quality, Physiology and Disease Research Unit, Pullman, WA 99164-6420, USA

Present Address:

O. Riera-Lizarazu

Dryland Cereals Research Program,

International Crops Research Institute for the Semi Arid Tropics,

Patancheru 502 324, Andhra Pradesh, India quantitative trait mapping using a recombinant inbred line population derived from a cross between a common soft wheat line and a genotype classified as an 'extra-soft' line. A total of 47 significant quantitative trait loci (QTL) ( $L O D \geq 3.0$ ) were identified for nine traits with the number of QTL affecting each trait ranging from three to nine. The percentage of phenotypic variance explained by these QTL ranged from 3.7 to $50.3 \%$. Six QTL associated with kernel hardness and break flour yield were detected on chromosomes 1BS, 4BS, 5BS, 2DS, 4DS, and 5DL. The two most important QTL were mapped onto orthologous regions on chromosomes 4DS (Xbarc1118-Rht-Dl) and 4BS $(X w m c 617-R h t-B 1)$. These results indicated that the 'extra-soft' characteristic was not controlled by the Hardness $(\mathrm{Ha})$ locus on chromosome 5DS. QTL for eight agronomic traits occupied two genomic regions near semidwarf genes Rht-Dl on chromosome 4DS and Rht-Bl on chromosome 4BS. The clustering of these QTL is either due to the pleiotropic effects of single genes or tight linkage of genes controlling these various traits.

\section{Introduction}

Improvement of flour yield and milling quality is an important objective in wheat (Triticum aestivum L.) breeding programs. Kernel hardness is used as a criterion to separate wheat into two market classes, hard and soft. Flour from soft-grained wheat is generally used for pastry-type end-use applications, such as cookies and cakes, rather than bread-based products. In addition to being a fundamental distinction between two wheat market classes, kernel hardness is a complex trait affecting milling, baking, and other end-uses of wheat. Within the soft wheat class, genotypes with consistently softer grains are described as 
'extra-soft'. 'Extra-soft' wheat has higher break flour yield and superior milling quality relative to common soft wheat. This is consistent with a negative correlation reported between kernel hardness and flour yield (Parker et al. 1999).

This 'extra-soft' characteristic, which positively affects end-use quality relative to common soft wheat, has fostered interest in developing a novel market class of soft wheat. In turn, the economic potential of this new class of wheat has created an interest in understanding the genetic basis of the 'extra-soft' grain characteristic. Substantial efforts have been devoted to mapping and characterizing the underlying biochemical and genetic basis for the variation of wheat grain texture. From a biochemical perspective, Greenwell and Schofield (1986) determined that the protein friabilin was intricately associated with grain hardness. Friabilin is present in soft wheat, but it is partially or completely absent in hard wheat grains. Friabilin is composed of two proteins, termed puroindolines, encoded by $\operatorname{pin} A$ and $\operatorname{pin} B$ at the Hardness $\mathrm{Ha}$ ) locus on the short arm of chromosome 5D (Jolly et al. 1996; Mattern 1973). Since puroindolines are associated with polar lipids and endosperm membranes (Jolly et al., 1996), puroindolines have been proposed to be the causal agents for the soft grain phenotype in wheat (Giroux and Morris, 1998). Studies using transgenic wheat have now shown that the soft wheat phenotype is primarily controlled by the pinB-D1b allele (Beecher et al. 2002; Hogg et al. 2004).

In addition to the $\mathrm{Ha}$ locus and puroindoline genes, a number of QTL that affect wheat grain hardness have been identified in different mapping populations (Breseghello et al. 2005; Campbell et al. 1999; Nelson et al. 2006; Sourdille et al. 1996). Sourdille et al. (1996) reported four regions on chromosomes $2 \mathrm{~A}, 2 \mathrm{D}, 5 \mathrm{~B}$, and $6 \mathrm{D}$ that contribute to the degree of hardness, while three other loci having an indirect effect on kernel hardness are located on chromosomes 5A, 6D, and 7A. Most recently, a major QTL for grain hardness has been mapped onto chromosome $1 \mathrm{BL}$, accounting for $28 \%$ of the phenotypic variance for kernel hardness, while only $8 \%$ of the phenotypic variance was explained by the QTL mapped closely to the Ha locus and the puroindoline genes on 5DS (Li et al. 2009). Ten out of 19 QTL for grain hardness were located on the same chromosome regions as the QTL for grain protein content, wet gluten content, or water absorption (Li et al. 2009). These results indicate that kernel hardness is controlled by many QTL, and these QTL may affect other related traits.

Most genetic studies on wheat kernel hardness have focused on the difference between soft and hard grain, but little work has been done on the genetic factors controlling the difference between soft and 'extra-soft' grain. To better understand the genetic control of the 'extra-soft' characteristic, we developed a $\mathrm{F}_{5: 6}$ recombinant inbred line (RIL) mapping population derived from a cross between the soft white wheat cultivar 'Stephens' (hardness index 24) and 'OR9900553' (hardness index 12), an elite breeding line with the 'extra-soft' grain characteristic. Although the objective of this study was to identify the underlying genetic factors controlling the 'extra-soft' characteristic by detecting QTL for kernel hardness, the mapping population was also used to identify and locate QTL associated with three end-use related traits, break flour yield, bran recovered flour yield, and unground middling flour yield; and five other agronomic traits. We also determined whether the semi-dwarfing genes $R h t-B l$ and $R h t-D l$ influenced wheat endosperm texture, in order to clarify associations between these semi-dwarfing genes and kernel hardness.

\section{Materials and methods}

Plant materials and experimental design

The OS9 $\times$ Q36 wheat mapping population consisted of $164 \mathrm{~F}_{5: 6}$-derived RILs generated from a cross between soft white winter (SWW) wheat OS9A (Stephens) and 'extrasoft' white wheat QCB36 (OR9900553). OS9A is a single plant selection from the cultivar 'Stephens', a widely adapted and high-yielding semi-dwarf variety with durable high-temperature adult-plant (HTAP) resistance to stripe rust (Puccinia striiformis Westend f. sp. tritici Ericks) (Chen and Line, 1995). QCB36 is a single plant selection from the elite breeding line OR9900553, a high-yielding and facultative semi-dwarf white wheat breeding line, with 'extra-soft' grain kernel texture and superior end-use quality also known to carry the $2 \mathrm{~N}^{\mathrm{v}} \mathrm{S}-2 \mathrm{AS} .2 \mathrm{AL}, 5 \mathrm{~B}: 7 \mathrm{~B}$, and 1BL.1RS chromosome translocations (Riera-Lizarazu et al. 2010). The parents contributed contrasting alleles of two gibberellic acid (GA)-insensitive, semi-dwarfing genes, Rht-Bl and Rht-Dl. The parent OS9A carried the semi-dwarf allele $R h t-B 1 b$ and the tall allele $R h t-D l a$, while QCB36 carried the tall allele Rht-Bla and the semidwarf allele at $R h t-D 1 b$. Also, QCB36 has a spring allele at the vernalization response gene $V r n 1-B 1$ whereas OS9A has the winter allele at this locus.

The OS9 $\times$ Q36 mapping population and its parents were grown in two environments in 2007: Hyslop Farm, Corvallis, OR (environment abbreviation CR07) and in the greenhouse at Oregon State University (GH07). In 2008, they were again planted in Corvallis (CR08), Moro (MR08), and Pendleton (PE08), in OR, Pullman, WA (PU08), and Moscow, ID (MC08). The RILs and their two parental lines were arranged in a randomized complete block design (RCBD) with two replications in each location. Phenotypic traits including days to heading (HDD), plant height (PHT), test weight (TWT), and grain protein 
content (GPC), were collected for RILs in all six field environments. The kernel hardness (KHA), thousand-kernel weight (TKW), and kernel diameter (KDM) were collected for the mapping population from the greenhouse and Hyslop Farm in Corvallis in 2007 and the other five field environments in 2008. Milling-related traits including break flour yield (BFY), bran recovered flour (BRN), and unground middling flour (MID), were evaluated for environments CR08, MR08, PE08, and PU08.

\section{Statistical analysis of phenotypic data}

The phenotypic data for each trait across environments were analyzed for normality by PROC UNIVARIATE procedure of SAS 9.2 (SAS Institute, Cary, NC). On the basis of these normality tests, all trait data showed normal distribution or nearly normal distribution. In order to estimate the interaction effect of genotype by environment $(\mathrm{G} \times \mathrm{E})$, analysis of variance (ANOVA) was performed using PROC MIXED procedures, where all effects were assumed random. Phenotypic correlation coefficients among traits were estimated using PROC CORR in SAS for the data across four environments (CR08, MR08, PE08, and PU08). Least square (LS) means for the various traits of each RIL in the individual environment and combined field environments (CB) were calculated using SAS as well.

Genotyping, linkage mapping, and QTL analysis

The two parents and 164 RILs were genotyped with simple sequence repeat (SSR) and diversity array technology (DArT) markers as described by Riera-Lizarazu et al. (2010). In addition, all RILs were genotyped with markers specific for semi-dwarfing alleles at the Rht-Bl and Rht-Dl loci and the vernalization response gene Vrn-B1. Assays for the gene-specific markers Rht-Bl and Rht-Dl were followed by protocols described by Ellis et al. (2002) and assays for $V r n-B 1$ followed by the procedure described by Fu et al. (2005). The two parental lines were genotyped for puroindoline alleles at the pinA and $\operatorname{pin} B$ loci on 5DS. Both parents were monomorphic for alleles at these loci. The linkage map based on this RIL mapping population was constructed using JoinMap 4 (Van Ooijen 2006) with the regression mapping method and the Kosambi mapping function. A genetic map with a length of 1,821 centiMorgans (cM) and an average density of one marker per $5.5 \mathrm{cM}$ was constructed. The genetic map used in QTL analysis was composed of 229 SSR markers, 38 DArT markers, and three gene-specific markers arranged in 45 linkage groups anchored to the 21 chromosomes of wheat. The order of marker loci in each linkage group was consistent with previous reports (Somers et al. 2004).
The genetic linkage map and least-square (LS) mean values of phenotypic traits were used in QTL analysis using interval mapping and multiple-QTL model (MQM) mapping implemented in MapQTL 5.0 (Van Ooijen 2004). The significant likelihood-odds (LOD) threshold corresponding to the genome wide significance at 0.05 levels was estimated with 1,000 permutations, resulting in LOD scores of 3.0-3.5 for all the investigated traits. Interval mapping was first performed to identify significant QTL at a $1 \mathrm{cM}$ interval. The marker closest to the significant LOD peak at each linkage was selected as a cofactor, and then all the selected markers were used as genetic background controls in MQM analysis. If the inclusion of cofactors led to the identification of new significant QTL, the new cofactor(s) was included in subsequent MQM analysis. This process continued until no new significant QTL were detected and the final MQM model was obtained. Thus, significant QTL were declared from the final MQM model. The final linkage maps with approximate 1-LOD QTL intervals were drawn using MapChart 2.2 (Voorrips 2002).

\section{Results}

Distribution and correlation of phenotypic traits

All traits evaluated showed continuous variation at each of the environments and across the environments (Supplemental Figures 1-9). The LS means for KHA among RILs varied from 5.4 to 40.6 in a combined analysis across environments, showing that wheat kernel texture ranged from values typically associated with 'extra-soft' wheat to values typically associated with common soft wheat. Similarly, a continuous distribution was observed for BFY (range from 112 to $178 \mathrm{~g} / \mathrm{kg}$ ) in the RIL population. Compared with other environments, HDD were generally longer in the PU08 and MC08 environments.

According to the outputs of ANOVA, both genotype and environment main effects were highly significant $(P<0.001)$ for all phenotypic traits except the environmental main effect of MID $(P<0.01)$. The environmental variance components of all the traits were larger than corresponding genotypic variance components except $\mathrm{BFY}, \mathrm{BAN}$, and $\mathrm{MID}$, and $\mathrm{G} \times \mathrm{E}$ variance components were small. As for the correlation between traits, KHA had a negative correlation to BFY $(r=-0.502)$ and to BRN $(r=-0.273)$ across environments. Conversely, KHA had a positive correlation with MID $(r=0.597)$. Both KHA and BFY were associated positively with TWT $(r=0.110$ and $r=0.023$, respectively). Significant negative correlations were also observed between PHT and HDD $(r=$ $-0.449)$, and PHT and GPC ( $r=-0.122)$. 
QTL results

A total of 47 QTL were detected for nine traits (Fig. 1; Tables 1, 2). Among these, 24 QTL were detected in at least two environments, of which seven were significant in all environments. The number of QTL detected per trait ranged from three for MID to nine for TKW. The majority of significant QTL mapped to 16 wheat chromosomes in the B or D genomes. Only chromosomes 1D, 3A, 4A, 5A, and 6D lacked mapped QTL. The QTL peak position, the corresponding $R^{2}$ value (proportion of phenotypic variance explained by a QTL), 1-LOD QTL support limit, and the additive effect, are reported for each QTL in Table 2. Of these 47 QTL, five QTL for KHA, MID, PHT, and TWT explained more than $30 \%$ of the phenotypic variance, four QTL explained 20-30\% and 12 QTL explained 10-20\% of the phenotypic variance. In addition, both parents contributed high-value alleles for all traits except BRN and MID, and the direction of the additive effect of each QTL was consistent across different environments.

\section{Kernel hardness (KHA) QTL}

Five significant QTL were detected on four chromosomes (4BS, 4DS, 5DL, and 7DS) and explained 7.1-33.8\% of the phenotypic variance each with a LOD of 3.0 to 11.3 (Table 1; Fig. 1). Three QTL, Qkha.orr-4B, Qkha.orr-4D, and Qkha.orr-5D, were detected in at least three environments. The most significant QTL, Qkha.orr-4D, was identified on 4DS in an interval between Xbarc1118 and $R h t-D l$ in all seven environments and across environments with LOD scores ranging from 5.8 to 11.3 . This QTL explained $14.7-33.8 \%$ of the phenotypic variance for grain hardness with an additive effect of 2.7-4.6. Another prominent QTL, Qkha.orr-4B, mapped to an interval between $X w m c 617$ and $R h t-B 1$ in five environments and across environments, and accounted for $8.0-20.2 \%$ of the phenotypic variance with additive effects of 2.1-3.1. The Qkha.orr-5D interval on chromosome 5DL was significant in the PU08 and MC08 environments and across environments, explaining 7.6-10.2\% of the phenotypic variance with negative additive effects from 1.2 to 2.2. Another QTL on 4D and Qkha.orr-7D were detected only at CR07. Except for Qkha.orr-5D, other QTL had positive additive effects, indicating that KHA was increased by alleles from OS9A at these QTL loci.

\section{Break flour yield (BFY) QTL}

Six QTL were detected on chromosomes 1BS, 4BS, 5BS, 7BL, 2DS, and 4DS (Table 1; Fig. 1). Both Qbfy.orr-1B and $Q b f y . o r r-5 B$ were identified in three environments and across environments. The major QTL, Qbfy.orr-1B, was mapped to chromosome 1BS with a narrow 1-LOD support limit interval between RIS and marker Xbarc240. It explained $9.1-15.6 \%$ of the phenotypic variance with additive effects of 4.3-5.9. Another QTL, Qbfy.orr-5B, was consistently detected near marker locus XwPt-0103 on 5BS with LOD scores of 3.6-10.8, and explained 8.9-19.9\% of the phenotypic variance. The Qbfy.orr-4D QTL was mapped between semi-dwarfing gene $R h t-D l$ and marker Xbarc1118 on 4DS with negative additive effects ranging from 6.2 to 8.9. Three QTL Qbfy.orr-4B, Qbfy.orr-7B, and Qbfy.orr-2D were detected only in a single environment, and accounted for 9.9, 11.9, and $7.3 \%$ of the phenotypic variance, respectively.

\section{Bran recovered flour (BRN) QTL}

A total of five QTL were identified on chromosomes 6AL, 1BS, 4BS, 5BL, and 4DS (Table 1; Fig. 1). The most significant QTL, Qbrn.orr-1B, was detected in all environments and across environments with LOD scores ranging from 6.7 to 12.2 . This QTL explained 6.9-23.6\% of the phenotypic variance with additive effects ranging from 4.9 to 8.1. Another major QTL, Qbrn.orr-4D, was detected at three environments and across environments with LOD scores ranging from 5.3 to 11.2. This QTL was consistently located in the interval between markers Xbarcl118 and Rht-Dl and the phenotypic variance explained by this QTL ranged from 15.5 to $26.2 \%$ with negative additive effects from 8.2 to 10.7. Other QTL on chromosome 6AL, 4BS, and 5BL were only detected at $\mathrm{CB}$ (combined field environments), CR08, and CR08, and accounted for $5.8,6.9$, and $6.1 \%$ of the phenotypic variance, respectively. The parent Q36 contributed the lower value allele to all the five QTL, indicating that QCB36 possessed alleles decreasing BRN.

Fig. 1 Genetic linkage map of wheat showing quantitative trait loci (QTLs) mapped to 16 chromosomes in the OS9 $\times$ Q36 RIL mapping population. The approximate 1-LOD supported intervals for QTLs are indicated by vertical bars. The additive effects contributed by 'Stephens' and 'OR9900553' are indicated by solid boxes and open boxes on the left side of each linkage group, respectively. Chromosome segments shown in black indicate the approximate position of the centromere inferred from the wheat microsatellite consensus map (Somers et al. 2004). QTL abbreviations for traits: Qkha.orr kernel hardness, Qbfy.orr break flour yield, Qbrn.orr bran recovered yield, Qmid.orr middling flour yield, Qpht.orr plant height, Qhdd.orr days to heading, Qtwt.orr test weight, Qgpc.orr grain protein content, Qtkw.orr thousand-kernel weight. Abbreviations of environments in which the QTLs were detected are given in brackets: 1, Corvallis (OR), 2007; 2, Corvallis (OR), 2008; 3, Moro (OR), 2008; 4, Pendleton (OR), 2008; 5, Pullman (WA), 2008; 6, Moscow (ID), 2008; 7, Greenhouse, 2007; and C, Combined across field environments 
$1 \mathrm{~A}$

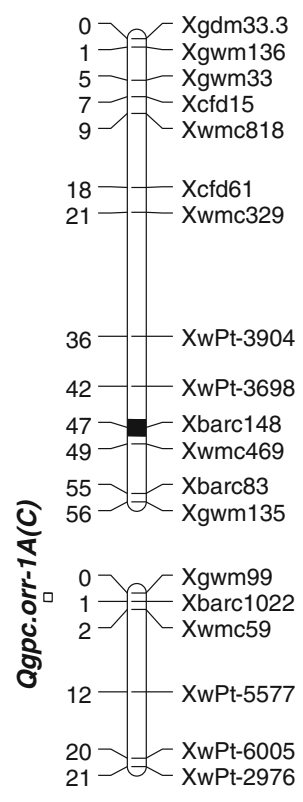

2D

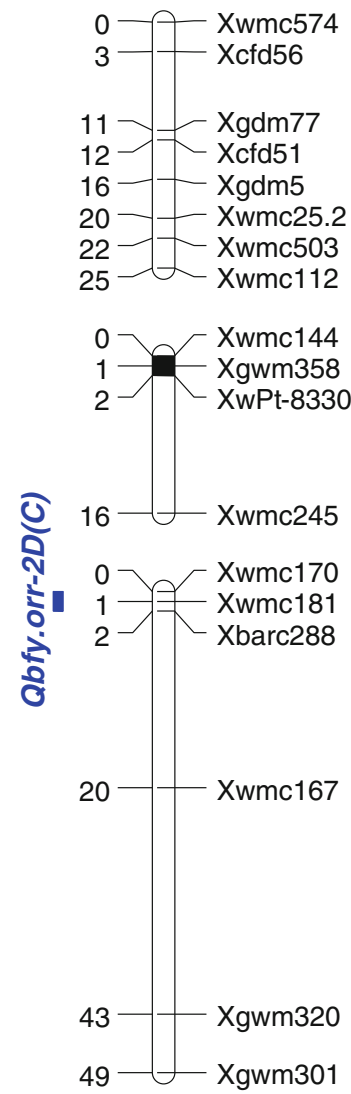

1B

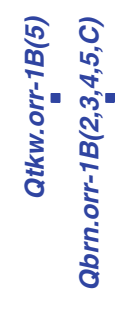

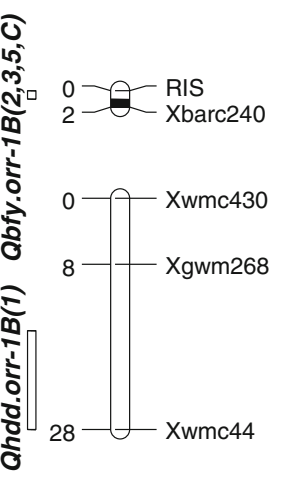

$2 A$

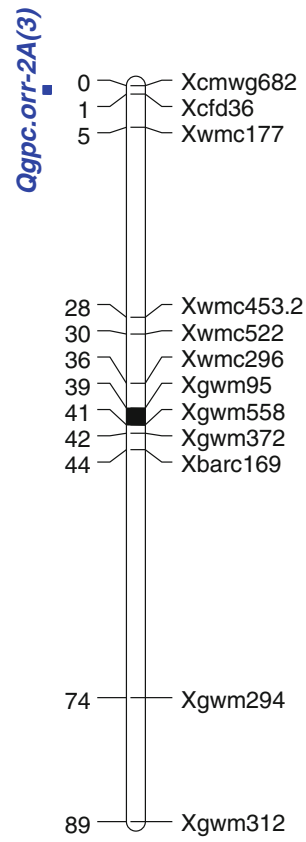

2B

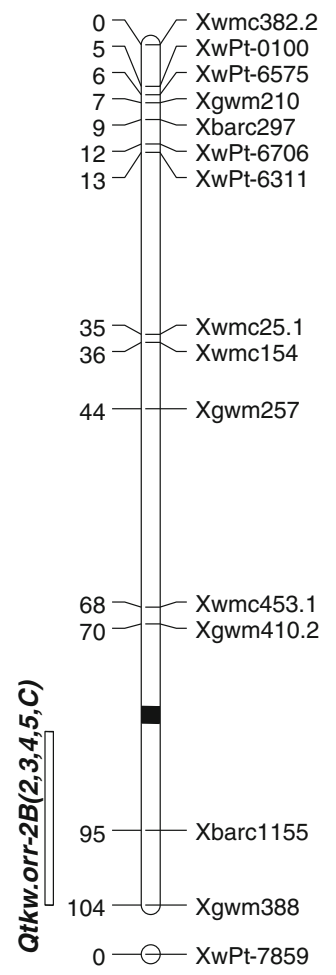

3B

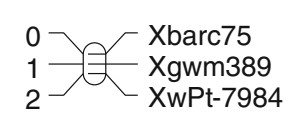

$0-\odot$ XwPt-8855

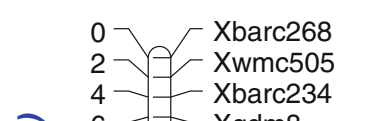

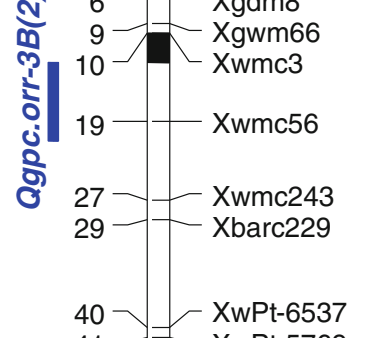

3D
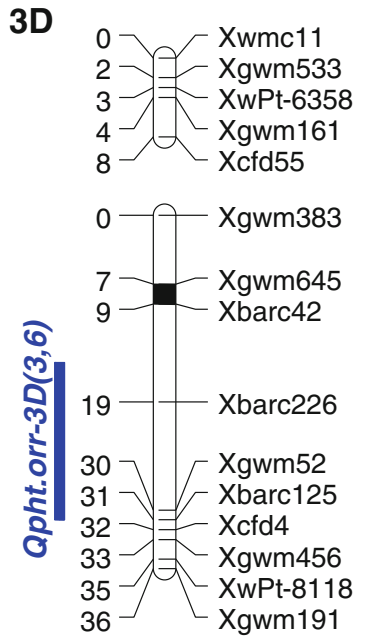

XwPt-5769
XwPt-7436

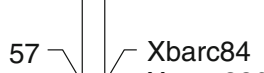

$61-$ Xwmc326.2

63 - Xwmc510

$64-X w m c 326.1$

$65->$ Xbarc77

$66-$ XwPt-4933

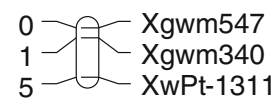


4B

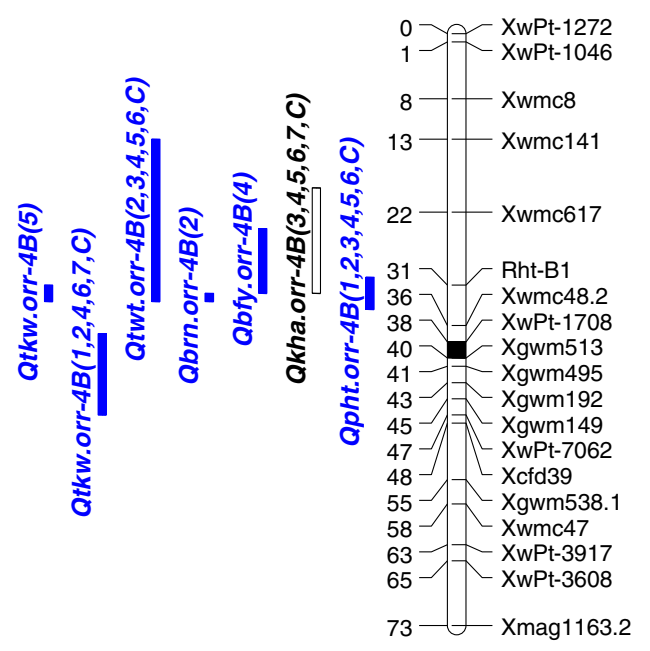

5B
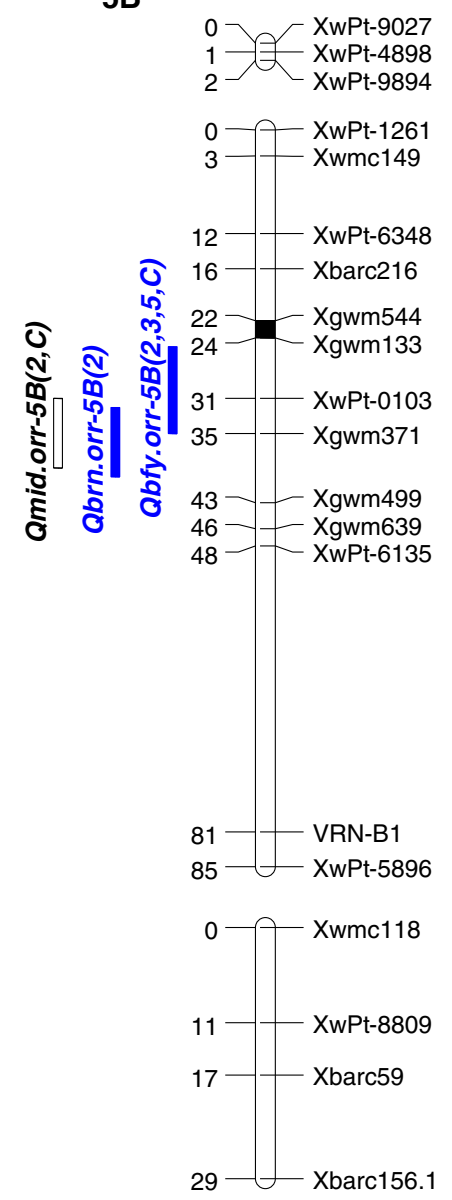

4D

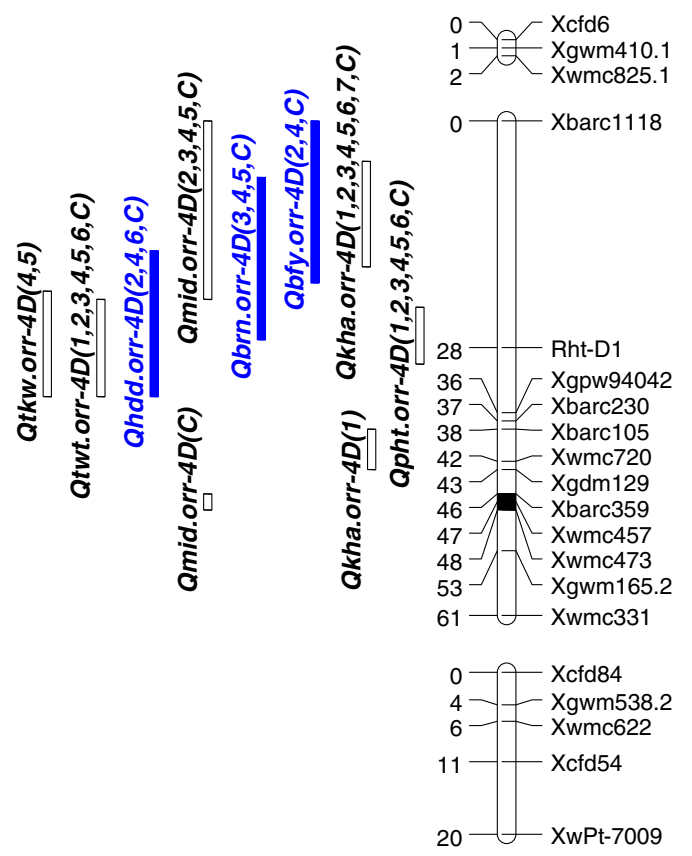

5D

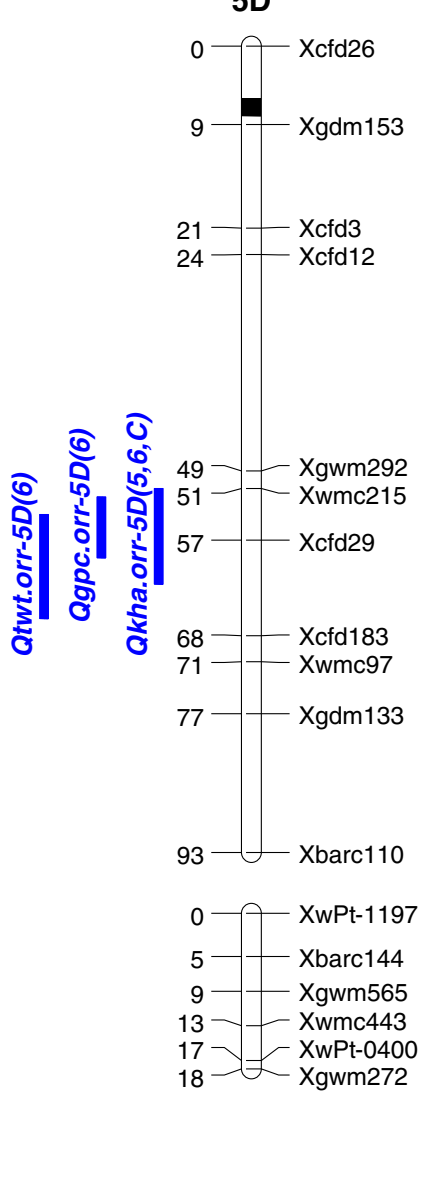

$6 A$

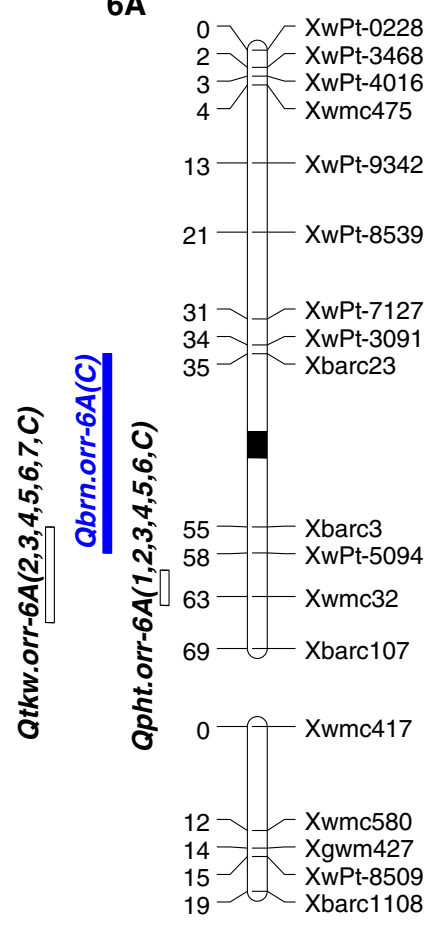

Fig. 1 continued 
6B

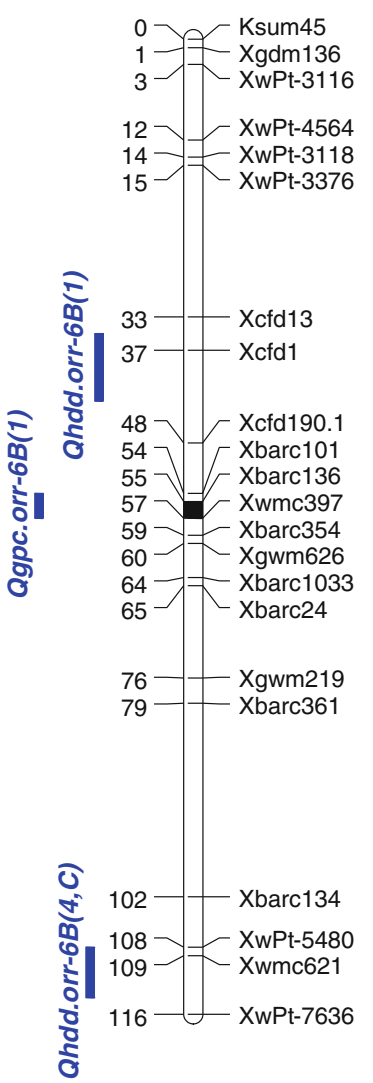

7A

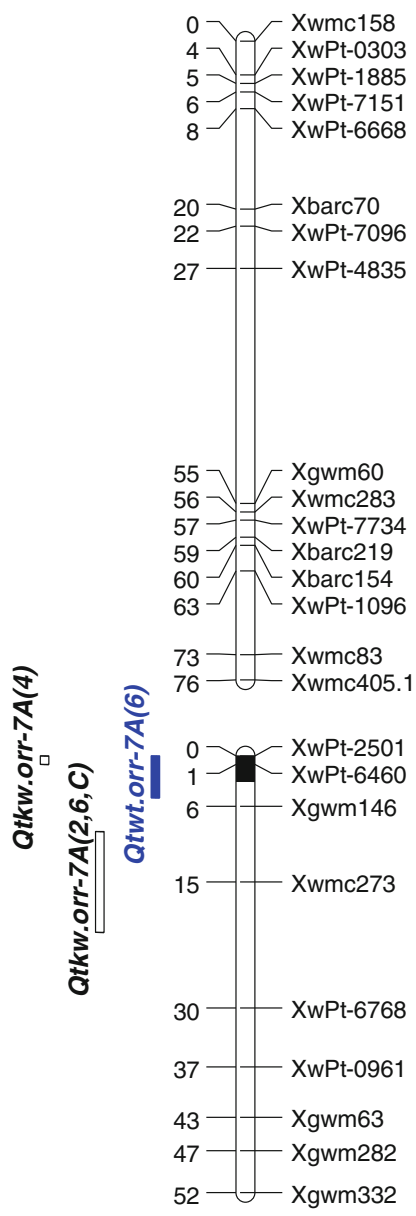

7B

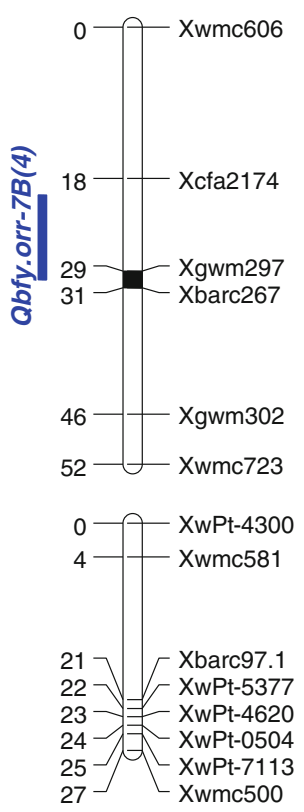

7D

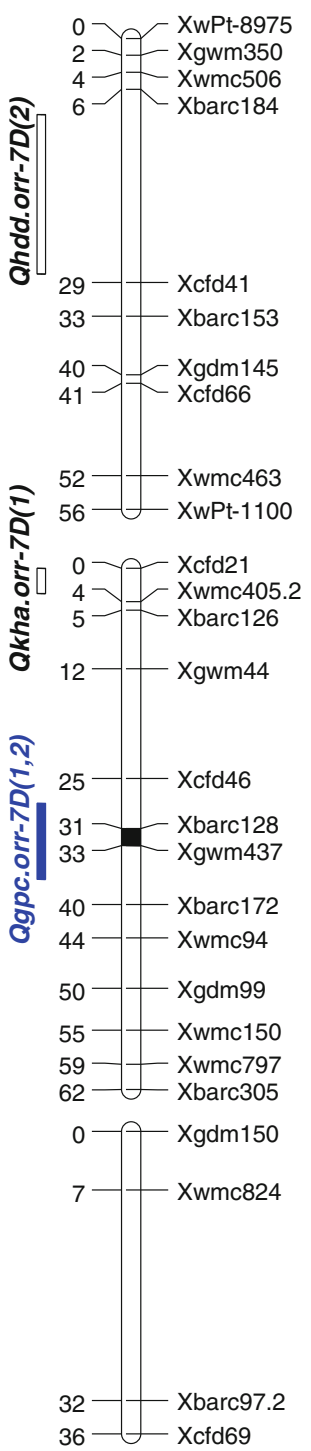

Fig. 1 continued

Unground middling flour (MID) QTL

Three significant QTL were identified on chromosomes 5BL, 4DS, and 4DL for MID (Table 1; Fig. 1). The QTL Qmid.orr-4D on 4DS was detected in all four environments and across environments with LOD scores of 8.6-16.2. It explained $18.3-47.6 \%$ of the phenotypic variance with additive effects ranging from 9.0 to 18.2. The Qmid.orr-5B QTL was detected at CR08 and across environments, accounting for 14.5 and $11.9 \%$ of the phenotypic variance with additive effects of 7.8 and 6.9, respectively. In contrast to the QTL for BRN, all major and minor QTL for MID were contributed by OS9A alleles that increased MID.
Plant height (PHT) QTL

Among four significant QTL detected, three QTL on chromosomes 6AL, 4BS, and 4DS were detected in all environments, while Qpht.orr-3D was detected only in two environments (Table 2; Fig. 1). Two major QTL were mapped onto semi-dwarfing genes Rht-Bl and Rht-Dl with LOD scores up to 36.1 and 41.6 , respectively. These two QTL explained up to $80 \%$ of the total phenotypic variance in plant height across six field environments. The Qpht.orr$4 B$ explained $15.3-36.1 \%$ of the phenotypic variance with a negative additive values ranging from 3.7 to 11.1. Qpht.orr$4 D$ accounted for $28.0-50.3 \%$ of phenotypic variance with additive effects ranging from 3.9 to 12.9. Two minor QTL 
Table 1 Summary of QTL for kernel hardness (KHA), break flour yield (BFY), bran yield (BRN), and middling yield (MID) using the OS9 $\times$ Q36 RIL population

\begin{tabular}{|c|c|c|c|c|c|c|c|}
\hline $\begin{array}{l}\text { Trait and QTL } \\
\text { symbol }\end{array}$ & $\begin{array}{l}\text { Environment } \\
\text { abbreviation }\end{array}$ & $\begin{array}{l}\text { Chromo-some } \\
\mathrm{arm}^{\mathrm{a}}\end{array}$ & QTL peak ${ }^{\mathrm{b}}$ & $\mathrm{LOD}^{\mathrm{c}}$ & 1-LOD support limit ${ }^{\mathrm{d}}$ & $R^{2 \mathrm{e}}(\%)$ & $\begin{array}{l}\text { Additive } \\
\text { effect }^{\mathrm{f}}\end{array}$ \\
\hline KHA & GH07 & 4BS & $26(X w m c 617)$ & 3.7 & 19-31 (Xwmc617-Rht-B1) & 9.3 & 2.3 \\
\hline \multirow[t]{18}{*}{ Qkha.orr } & & 4DS & $13($ Xbarc 1118) & 10.9 & 7-18 (Xbarc1118-Rht-D1) & 33.8 & 4.6 \\
\hline & CR07 & 4DS & $6($ Xbarc1118) & 5.8 & 0-16 (Xbarc1118-Rht-D1) & 14.7 & 2.7 \\
\hline & & 4DS & $40(X w m c 720)$ & 3.8 & 38-43 (Xbarc105-Xwmc720) & 8.5 & 2.0 \\
\hline & & 7DS & $0(X c f d 21)$ & 3.4 & $0-3(X c f d 21-X w m c 405.2)$ & 7.1 & 1.7 \\
\hline & CR08 & 4DS & $17(R h t-D 1)$ & 11.3 & 11-22 (Xbarc1118-Rht-D1) & 33.8 & 4.2 \\
\hline & MR08 & 4BS & $25(R h t-B 1)$ & 3.0 & 22-29 (Xwmc141-Rht-B1) & 8.0 & 2.1 \\
\hline & & 4DS & $16(R h t-D 1)$ & 8.8 & 10-22 (Xbarc1118-Rht-D1) & 27.5 & 4.1 \\
\hline & PE08 & 4BS & $27($ Rht-B1) & 7.9 & 25-30 (Xwmc617-Rht-B1) & 20.2 & 3.1 \\
\hline & & 4DS & $11($ Xbarc1118) & 7.8 & 4-17 (Xbarc1118-Rht-D1) & 22.7 & 3.3 \\
\hline & PU08 & 4BS & $27(R h t-B 1)$ & 4.1 & 24-32 (Xwmc617-Rht-B1) & 10.8 & 2.4 \\
\hline & & 4DS & $12($ Xbarc 1118) & 7.2 & 3-18 (Xbarc1118-Rht-D1) & 20.9 & 3.4 \\
\hline & & $5 \mathrm{DL}$ & $54(X w m c 215)$ & 3.4 & 50-57 (Xgwm292-Xcfd29) & 8.0 & -1.2 \\
\hline & MC08 & 4BS & $28(R h t-B 1)$ & 4.9 & 23-32 (Xwmc617-Rht-B1) & 12.2 & 2.5 \\
\hline & & 4DS & $11($ Xbarc1118) & 6.6 & 2-18 (Xbarc1118-Rht-D1) & 18.7 & 3.2 \\
\hline & & $5 \mathrm{DL}$ & $54(X c f d 29)$ & 4.6 & $51-60(X w m c 215-X c f d 29)$ & 10.2 & -2.2 \\
\hline & $\mathrm{CB}$ & 4BS & $27(R h t-B 1)$ & 5.4 & 24-30 (Xwmc617-Rht-B1) & 13.3 & 2.4 \\
\hline & & 4DS & $12($ Xbarc 1118) & 9.4 & 5-18 (Xbarc1118-Rht-D1) & 25.7 & 3.4 \\
\hline & & $5 \mathrm{DL}$ & $55(X c f d 29)$ & 3.5 & $51-62(X w m c 215-X c f d 29)$ & 7.6 & -1.7 \\
\hline BFY & CR08 & $1 \mathrm{BS}$ & $0(R I S)$ & 4.2 & $0-1(R I S-X b a r c 240)$ & 9.1 & 4.3 \\
\hline \multirow[t]{13}{*}{ Qbfy.orr } & & $5 \mathrm{BS}$ & $31(X w P t-0103)$ & 4.1 & 27-35 (Xgwm133-Xgwm371) & 8.9 & -4.1 \\
\hline & & 4DS & $11($ Xbarc1118) & 6.9 & 3-18 (Xbarc1118-Rht-D1) & 20.0 & -7.0 \\
\hline & MR08 & $1 \mathrm{BS}$ & $0(R I S)$ & 6.1 & $0-1(R I S-X b a r c 240)$ & 14.0 & 5.9 \\
\hline & & $5 \mathrm{BS}$ & $29(X w P t-0103)$ & 6.5 & 25-33 (Xgwm133-XwPt-0103) & 15.7 & -6.3 \\
\hline & PE08 & 4BS & $28(R h t-B 1)$ & 3.9 & 24-32 (Xwmc617-Rht-B1) & 9.9 & -5.5 \\
\hline & & $7 \mathrm{BL}$ & $25(X g w m 297)$ & 4.8 & 20-30 (Xcfa2174-Xgwm297) & 11.9 & -5.8 \\
\hline & & 4DS & $11($ Xbarc1118) & 4.2 & 0-20 (Xbarc1118-Rht-D1) & 12.2 & -6.2 \\
\hline & PU08 & $1 \mathrm{BS}$ & $0(R I S)$ & 4.4 & $0-2(R I S-X b a r c 240)$ & 10.9 & 4.3 \\
\hline & & $5 \mathrm{BS}$ & $33(X w P t-0103)$ & 3.6 & 25-35 (Xgwm133-Xgwm371) & 9.0 & -3.9 \\
\hline & $\mathrm{CB}$ & 1BS & $0(R I S)$ & 8.9 & $0-1(R I S-X b a r c 240)$ & 15.6 & 4.9 \\
\hline & & $5 B S$ & $30(X w P t-0103)$ & 10.8 & 27-34 (Xgwm133-Xgwm371) & 19.9 & -5.4 \\
\hline & & 2DS & $1($ Xwmc181) & 4.4 & 0-2 (Xwmc170-Xbarc288) & 7.3 & -3.3 \\
\hline & & 4DS & $11($ Xbarc1118) & 8.9 & 4-17 (Xbarc1118-Rht-D1) & 19.2 & -8.9 \\
\hline BRN & CR08 & $1 \mathrm{BS}$ & $0(R I S)$ & 12.1 & $0-2(R I S-X b a r c 240)$ & 20.9 & -7.3 \\
\hline \multirow[t]{11}{*}{ Qbrn.orr } & & 4BS & $35(X w m c 48.2)$ & 4.3 & 32-38 (Rht-B1-XwPt-1708) & 6.9 & -4.2 \\
\hline & & $5 \mathrm{BL}$ & $35(X g w m 371)$ & 4.0 & 32-40 (XwPt-0103-Xgwm499) & 6.1 & -3.8 \\
\hline & MR08 & $1 \mathrm{BS}$ & $0(R I S)$ & 6.9 & $0-2(R I S-X b a r c 240)$ & 16.3 & -8.1 \\
\hline & & 4DS & $15(R h t-D 1)$ & 5.3 & 7-23 (Xbarc1118-Rht-D1) & 15.5 & -8.9 \\
\hline & PE08 & $1 \mathrm{BS}$ & $0(R I S)$ & 3.7 & $0-2(R I S-X b a r c 240)$ & 6.9 & -4.9 \\
\hline & & 4DS & $19($ Rht $-D 1)$ & 9.2 & 13-27 (Xbarc1118-Rht-D1) & 25.7 & -10.7 \\
\hline & PU08 & $1 \mathrm{BS}$ & $0(R I S)$ & 6.7 & $0-2(R I S-X b a r c 240)$ & 14.7 & -6.0 \\
\hline & & 4DS & $15(R h t-D 1)$ & 9.8 & 8-21 (Xbarc1118-Rht-D1) & 26.2 & -9.0 \\
\hline & $\mathrm{CB}$ & $6 \mathrm{AL}$ & 47 (Xbarc3) & 3.1 & 35-58 (Xbarc23-Xbarc3) & 5.8 & -3.7 \\
\hline & & 1BS & $0(R I S)$ & 12.2 & 0-2 (RIS-Xbarc240) & 23.6 & -7.1 \\
\hline & & 4DS & $16(R h t-D 1)$ & 11.2 & 10-21 (Xbarc1118-Rht-D1) & 25.4 & -8.2 \\
\hline MID & CR08 & $5 \mathrm{BL}$ & $33(X w P t-0103)$ & 7.6 & 31-35 (XwPt-0103-Xgwm371) & 14.5 & 7.8 \\
\hline Qmid.orr & & 4DS & $3($ Xbarc1118) & 8.6 & 0-11 (Xbarc1118-Rht-D1) & 18.3 & 9.0 \\
\hline
\end{tabular}


Table 1 continued

\begin{tabular}{|c|c|c|c|c|c|c|c|}
\hline $\begin{array}{l}\text { Trait and QTL } \\
\text { symbol }\end{array}$ & $\begin{array}{l}\text { Environment } \\
\text { abbreviation }\end{array}$ & $\begin{array}{l}\text { Chromo-some } \\
\operatorname{arm}^{\mathrm{a}}\end{array}$ & QTL peak $^{\text {b }}$ & $\mathrm{LOD}^{\mathrm{c}}$ & 1-LOD support limit ${ }^{\mathrm{d}}$ & $R^{2 \mathrm{e}}(\%)$ & $\begin{array}{l}\text { Additive } \\
\text { effect }^{\mathrm{f}}\end{array}$ \\
\hline & & 4DS & $42(X w m c 720)$ & 3.6 & 40-43 (Xbarc106-Xgdm129) & 6.4 & 5.2 \\
\hline & MR08 & 4DS & $16(R h t-D 1)$ & 10.4 & 10-22 (Xbarc1118-Rht-D1) & 33.4 & 14.0 \\
\hline & PE08 & 4DS & $17(R h t-D 1)$ & 16.2 & 12-20 (Xbarc1118-Rht-D1) & 47.6 & 18.2 \\
\hline & PU08 & 4DS & $15(R h t-D 1)$ & 15.6 & 11-20 (Xbarc1118-Rht-D1) & 45.3 & 14.5 \\
\hline & $\mathrm{CB}$ & $5 B L$ & $34($ Xgwm371) & 6.5 & 32-39 (XwPt-0103-Xgwm371) & 11.9 & 6.9 \\
\hline & & 4DS & $12($ Rht-Dl) & 14.2 & 7-19 (Xbarc1118-Rht-D1) & 34.7 & 12.9 \\
\hline & & $4 \mathrm{DL}$ & 47 (Xwmc457) & 4.5 & 46-48 (Xbarc359-Xwmc473) & 7.6 & 5.2 \\
\hline
\end{tabular}

CR07 Corvallis (OR), 2007; CR08 Corvallis (OR), 2008; MR08 Moro (OR), 2008; PE08 Pendleton (OR), 2008; PU08 Pullman (WA), 2008; MC08 Moscow (ID), 2008; $C B$ combined across field environments

${ }^{a}$ The letter $\mathrm{S}$ represented the short arm of chromosome, and $\mathrm{L}$ indicated the long arm of chromosome

${ }^{b}$ Position of QTL peak is expressed in centiMorgans (cM), nearest locus to QTL peak is indicated in brackets

${ }^{c}$ Logarithm of the odds ratio (LOD) of QTL peak that exceeded the significant LOD threshold from 1,000 permutations

d The flanking loci of 1-LOD support limit are indicated in brackets

${ }^{\text {e }} R^{2}$ is the proportion of the phenotypic variance explained by the QTL after accounting for co-factors

${ }^{\mathrm{f}}$ Positive additive values indicate that higher value alleles are from Stephens (OS9A) and the negative values indicate that the higher value alleles are from OR9900553 (QCB36)

on chromosomes 6AL and 3DL explained $4.3-9.8 \%$ and $3.7-5.1 \%$ of the phenotypic variance, respectively. The negative additive effects of Qpht.orr-4B (Rht-B1) and Qpht.orr-3D indicate that PHT was decreased by the alleles from QCB36 at these loci. On the other hand, the positive additive effects of Qpht.orr- $4 D(R h t-D l)$ indicate that OS9A contributed alleles at this locus that decreased PHT.

\section{Days to heading (HDD) QTL}

Five QTL were identified on chromosomes 1BL, 6BS, 6BL, 4DS, and 7DS, but no significant loci were detected at MR08 and PU08 (Table 2; Fig. 1). The QTL Qhdd.orr-4D was mapped onto the interval between Rht-Dl and Xgpw94042. The phenotypic variance explained by this QTL ranged from 11.3 to $21.6 \%$ with negative additive effects ranging from 0.6 to 1.3 in three environments and across environments. The Qhdd.orr-6B QTL, mapped to the interval between XwPt-5480 and Xwmc621 at PE08 and across environments, explained 10.4 and $7.5 \%$ of the phenotypic variance with negative additive effects of 0.7 and 0.4, respectively. Both Qhdd.orr-1B and Qhdd.orr-7D were significant only at CR08, accounting for 9.0 and $9.9 \%$ of the phenotypic variance with additive effects of 0.8 and 0.9 , respectively. Although HDD showed continuous variation, over $50 \%$ of the RILs headed within 3 days in all environments except at CR08. This lack of variation indicated that no major locus with a large effect for HDD segregated in the OS9 $\times$ Q36 population.

\section{Test weight (TWT) QTL}

Four QTL were identified on chromosomes 7AL, 4BS, 4DS, and 5DL (Table 2; Fig. 1). Qtwt.orr-4D, mapped to the interval between Rht-Dl and Xgpw94042, was detected in six environments and across environments with LOD scores ranging from 4.0 to 15.8. This QTL explained $10.0-30.9 \%$ of the phenotypic variance with additive effects ranging from 6.1 to 18.6. Qtwt.orr-4B, located in the interval between $X w m c 617$ and Rht-B1, was detected in five environments and across environments, accounting for $8.3-30.7 \%$ of the phenotypic variance with negative additive values ranging from 5.2 to 18.3. Both Qtwt.orr$7 A$ and Qtwt.orr-5D were identified only at MC08, and explained 9.6 and $9.3 \%$ of the phenotypic variance, respectively.

\section{Grain protein content (GPC) QTL}

A total of six significant QTL were mapped to chromosomes 1AL, 2AS, 3BL, 6BS, 5DL, and 7DL (Table 2; Fig. 1). Of these, Qgpc.orr-7D was detected at two environments; other QTL were significant only in single environments while no significant QTL was detected at PE08 or PU08. Qgpc.orr-7D explained 9.8 and $7.6 \%$ of the phenotypic variance with negative additive effects of 2.3 and 2.8 at CR07 and CR08, respectively. Besides Qgpc.orr-1A, all six QTL showed negative effects with QCB36 alleles decreasing GPC. 
Table 2 Summary of QTL for plant height (PHT), days to heading (HDD), test weight (TWT), grain protein content (GPC), and thousand-kernel weight $(\mathrm{TKW})$ using the OS9 $\times$ Q36 RIL population

\begin{tabular}{|c|c|c|c|c|c|c|c|}
\hline $\begin{array}{l}\text { Trait and } \\
\text { QTL symbol }\end{array}$ & $\begin{array}{l}\text { Environment } \\
\text { abbreviation }\end{array}$ & Chromosome arm $^{\mathrm{a}}$ & QTL peak $^{\mathrm{b}}(\mathrm{cM})$ & $\mathrm{LOD}^{\mathrm{c}}$ & 1-LOD support limit ${ }^{\mathrm{d}}$ & $R^{2 \mathrm{e}}(\%)$ & $\begin{array}{l}\text { Additive } \\
\text { effect }^{\mathrm{f}}\end{array}$ \\
\hline PHT & CR07 & $6 \mathrm{AL}$ & $61(X w m c 32)$ & 5.4 & 59-64 (XwPt-5094-Xwmc32) & 6.3 & 4.2 \\
\hline \multirow[t]{22}{*}{ Qpht.orr } & & 4BS & $31(R h t-B 1)$ & 21.1 & 30-32 (Rht-B1-Xwmc48.2) & 30.8 & -9.2 \\
\hline & & 4DS & $28(R h t-D 1)$ & 25.1 & 23-29 (Rht-D1-Xgpw94042) & 39.0 & 10.9 \\
\hline & CR08 & $6 \mathrm{AL}$ & $62(X w m c 32)$ & 11.2 & 60-64 (XwPt-5094-Xwmc32) & 8.6 & 5.0 \\
\hline & & 4BS & $31(R h t-B 1)$ & 34.2 & 31-32 (Xwmc617-Rht-B1) & 38.6 & -11.1 \\
\hline & & 4DS & $28(R h t-D 1)$ & 39.8 & 27-29 (Xbarc1118-Rht-D1) & 47.8 & 12.9 \\
\hline & MR08 & $6 \mathrm{AL}$ & $63(X w m c 32)$ & 3.8 & 59-64 (XwPt-5094-Xwmc32) & 5.4 & 1.6 \\
\hline & & 4BS & $32(R h t-B 1)$ & 15.3 & 30-34 (Rht-B1-Xwmc48.2) & 26.8 & -3.7 \\
\hline & & 3DL & $28(X g w m 52)$ & 3.4 & 22-31 (Xbarc226-Xgwm52) & 5.1 & -1.6 \\
\hline & & 4DS & $28(R h t-D 1)$ & 16.1 & 23-29 (Xbarc1118-Rht-D1) & 28.0 & 3.9 \\
\hline & PE08 & $6 \mathrm{AL}$ & $63(X w m c 32)$ & 6.2 & 60-65 (XwPt-5094-Xwmc32) & 4.3 & 3.0 \\
\hline & & 4BS & $31(R h t-B 1)$ & 36.1 & 31-32 (Xwmc617-Rht-B1) & 40.0 & -9.9 \\
\hline & & 4DS & $28(R h t-D 1)$ & 41.6 & 26-28 (Xbarc1118-Rht-D1) & 50.3 & 11.6 \\
\hline & PU08 & $6 \mathrm{AL}$ & $61(X w m c 32)$ & 8.1 & 59-63 (XwPt-5094-Xwmc32) & 9.8 & 3.2 \\
\hline & & 4BS & $31(R h t-B 1)$ & 19.4 & 31-32 (Rht-B1-Xwmc48.2) & 27.1 & -5.4 \\
\hline & & 4DS & $28(R h t-D 1)$ & 25.4 & 25-30 (Xbarc1118-Rht-D1) & 38.7 & 6.8 \\
\hline & MC08 & $6 \mathrm{AL}$ & $63(X w m c 32)$ & 7.9 & 60-64 (XwPt-5094-Xwmc32) & 8.2 & 3.2 \\
\hline & & 4BS & $31(R h t-B 1)$ & 22.2 & 30-33 (Xwmc617-Rht-B1) & 29.3 & -6.2 \\
\hline & & $3 \mathrm{DL}$ & $24($ Xbarc226) & 3.6 & 15-30 (Xbarc226-Xgwm52) & 3.7 & -2.2 \\
\hline & & 4DS & $28(R h t-D 1)$ & 28.1 & 26-29 (Xbarc1118-Rht-D1) & 40.5 & 7.7 \\
\hline & $\mathrm{CB}$ & $6 \mathrm{AL}$ & $62(X w m c 32)$ & 10.4 & 60-64 (XwPt-5094-Xwmc32) & 8.1 & 3.4 \\
\hline & & 4BS & $31(R h t-B 1)$ & 34.1 & 31-32 (Rht-B1-Xwmc48.2) & 38.6 & -7.6 \\
\hline & & 4DS & $28($ Rht-D1) & 38.3 & 26-28 (Xbarc1118-Rht-D1) & 46.2 & 8.9 \\
\hline HDD & CR07 & $6 \mathrm{BS}$ & $37(X c f d 1)$ & 3.4 & $35-43(X c f d 13-X c f d 1)$ & 8.3 & -0.6 \\
\hline \multirow[t]{10}{*}{ Qhdd.orr } & CR08 & $1 \mathrm{BL}$ & $28(X w m c 44)$ & 4.2 & 16-28 (Xgwm268-Xwmc44) & 9.0 & 0.8 \\
\hline & & 4DS & $28(R h t-D 1)$ & 9.4 & 21-31 (Rht-D1-Xgpw94042) & 21.6 & -1.3 \\
\hline & & 7DS & $18(X c f d 41)$ & 3.9 & 9-28 (Xbarc184-Xcfd41) & 9.9 & 0.9 \\
\hline & MR08 & No significant QTL & & & & & \\
\hline & PE08 & $6 \mathrm{BL}$ & $109($ Xwmc621) & 5.1 & 109-112 (XwPt-5480-Xwmc621) & 10.4 & -0.7 \\
\hline & & 4DS & $28(R h t-D 1)$ & 8.2 & 20-32 (Rht-D1-Xgpw94042) & 17.8 & -1.0 \\
\hline & PU08 & No significant QTL & & & & & \\
\hline & MC08 & 4DS & $25($ Rht-Dl) & 5.1 & 16-32 (Rht-D1-Xgpw94042) & 14.8 & -0.7 \\
\hline & $\mathrm{CB}$ & $6 \mathrm{BL}$ & $109($ Xwmc621) & 3.2 & 108-114 (XwPt-5480-Xwmc621) & 7.50 & -0.4 \\
\hline & & 4DS & $28(R h t-D 1)$ & 4.6 & 19-34 (Rht-D1-Xgpw94042) & 11.3 & -0.6 \\
\hline TWT & CR07 & 4DS & $28(R h t-D 1)$ & 6.0 & 23-32 (Rht-D1-Xgpw94042) & 16.3 & 6.7 \\
\hline \multirow[t]{12}{*}{ Qtwt.orr } & CR08 & 4BS & $27(R h t-B 1)$ & 4.1 & 24-30 (Xwmc617-Rht-B1) & 11.6 & -5.2 \\
\hline & & 4DS & $30(R h t-D 1)$ & 7.1 & 25-33 (Rht-D1-Xgpw94042) & 18.0 & 6.6 \\
\hline & MR08 & 4BS & $24(X w m c 617)$ & 3.1 & 13-29 (Xwmc141-Rht-B1) & 8.3 & -5.5 \\
\hline & & 4DS & $28(R h t-D 1)$ & 4.0 & 22-32 (Rht-D1-Xgpw94042) & 10.0 & 6.1 \\
\hline & PE08 & 4BS & $29(R h t-B 1)$ & 14.8 & 27-32 (Xwmc617-Rht-B1) & 30.7 & -18.3 \\
\hline & & 4DS & $28(R h t-D 1)$ & 15.8 & 26-30 (Rht-D1-Xgpw94042) & 30.9 & 18.6 \\
\hline & PU08 & 4BS & $30(R h t-B 1)$ & 11.0 & 28-33 (Xwmc617-Rht-B1) & 23.6 & -9.9 \\
\hline & & 4DS & $28(R h t-D 1)$ & 12.5 & 26-32 (Rht-D1-Xgpw94042) & 25.8 & 10.6 \\
\hline & MC08 & 7AL & $2(X w P t-6460)$ & 4.7 & $0-5(X w P t-2501-X g w m 146)$ & 9.6 & -4.4 \\
\hline & & 4BS & $26(R h t-B 1)$ & 3.7 & 22-30 (Xwmc617-Rht-B1) & 8.3 & -4.3 \\
\hline & & 4DS & $29($ Rht-D1) & 5.5 & 23-34 (Rht-D1-Xgpw94042) & 11.2 & 5.2 \\
\hline & & $5 \mathrm{DL}$ & $60(X c f d 29)$ & 4.5 & 54-66 (Xcfd29-Xcfd183) & 9.3 & -4.5 \\
\hline
\end{tabular}


Table 2 continued

\begin{tabular}{|c|c|c|c|c|c|c|c|}
\hline $\begin{array}{l}\text { Trait and } \\
\text { QTL symbol }\end{array}$ & $\begin{array}{l}\text { Environment } \\
\text { abbreviation }\end{array}$ & Chromosome arm ${ }^{\mathrm{a}}$ & QTL peak ${ }^{\mathrm{b}}(\mathrm{cM})$ & $\operatorname{LOD}^{\mathrm{c}}$ & 1-LOD support limit ${ }^{\mathrm{d}}$ & $R^{2 \mathrm{e}}(\%)$ & $\begin{array}{l}\text { Additive } \\
\text { effect }^{\mathrm{f}}\end{array}$ \\
\hline & $\mathrm{CB}$ & 4BS & $28(R h t-B 1)$ & 11.3 & 26-30 (Xwmc617-Rht-B1) & 24.2 & -8.3 \\
\hline & & 4DS & $28(R h t-D 1)$ & 14.7 & 26-31 (Rht-D1-Xgpw94042) & 30.3 & 9.3 \\
\hline GPC & CR07 & $6 \mathrm{BS}$ & $55($ Xbarc136) & 5.1 & 54-57 (Xbarc101-Xwmc397) & 13.0 & -2.6 \\
\hline \multirow[t]{8}{*}{ Qgpc.orr } & & $7 \mathrm{DL}$ & $32($ Xbarc128) & 3.9 & 28-33 (Xcfd46-Xgwm437) & 9.8 & -2.3 \\
\hline & CR08 & $3 B L$ & $16(X w m c 56)$ & 4.7 & 13-21 (Xwmc3-Xwmc56) & 13.7 & -3.9 \\
\hline & & $7 \mathrm{DL}$ & $33($ Xgwm437) & 3.0 & 31-37 (Xbarc128-Xgwm437) & 7.6 & -2.8 \\
\hline & MR08 & $2 \mathrm{AS}$ & $0($ Xcmwg682) & 3.4 & $0-1($ Xcmwg682-Xcfd36) & 9.2 & -2.5 \\
\hline & PE08 & No significant QTL & & & & & \\
\hline & PU08 & No significant QTL & & & & & \\
\hline & MC08 & $5 \mathrm{DL}$ & $57(X c f d 29)$ & 4.1 & $52-59(X w m c 215-X c f d 29)$ & 10.9 & -3.1 \\
\hline & $\mathrm{CB}$ & $1 \mathrm{AL}$ & $0(X g w m 99)$ & 4.1 & 0-1 (Xgwm99-Xbarc1022) & 10.6 & 5.2 \\
\hline TKW & GH07 & $6 \mathrm{AL}$ & $61(X w m c 32)$ & 3.8 & 58-64 (XwPt-5094-Xwmc32) & 9.3 & 1.8 \\
\hline \multirow[t]{26}{*}{ Qtkw.orr } & & 4BS & $36(X w m c 48.2)$ & 6.8 & 34-38 (Xwmc48.2-XwPt-1708) & 16.5 & -2.3 \\
\hline & CR07 & $4 \mathrm{BL}$ & $45(X g w m 149)$ & 4.7 & 44-47 (Xgwm192-XwPt-7062) & 12.9 & -1.2 \\
\hline & CR08 & $6 \mathrm{AL}$ & $62(X w m c 32)$ & 5.1 & 59-66 (XwPt-5094-Xwmc32) & 8.2 & 1.1 \\
\hline & & 7AL & $15(X w m c 273)$ & 5.8 & 12-20 (Xgwm146-XwPt6168) & 8.9 & 1.1 \\
\hline & & $2 \mathrm{BL}$ & 98 (Xbarc1155) & 5.1 & 87-103 (Xbarc1155-Xgwm388) & 8.3 & 1.1 \\
\hline & & 4BL & $41(X g w m 495)$ & 8.6 & 40-43 (Xgwm513-Xgwm495) & 13.8 & -1.5 \\
\hline & & $3 \mathrm{DL}$ & $16(X g w m 3)$ & 4.6 & 14-16 (Xwmc552-Xgwm3) & 6.9 & 1.0 \\
\hline & MR08 & $6 \mathrm{AL}$ & $59(X w P t-5094)$ & 4.1 & 56-63 (Xbarc3-XwPt-5094) & 10.4 & 1.0 \\
\hline & & $2 \mathrm{BL}$ & $98(X g w m 388)$ & 3.7 & 95-104 (Xbarc1155-Xgwm388) & 9.7 & 1.0 \\
\hline & PE08 & $6 \mathrm{AL}$ & $60(X w P t-5094)$ & 3.6 & 55-63 (Xbarc3-XwPt-5094) & 5.8 & 0.9 \\
\hline & & 7AL & $0(X w P t-2501)$ & 3.5 & $0-1(X w P t 2501-X w P t 6460)$ & 5.4 & 0.9 \\
\hline & & $2 \mathrm{BL}$ & $86($ Xbarc1155) & 4.1 & 77-100 (Xgwm410.2-Xbarc1155) & 7.7 & 1.2 \\
\hline & & 4BS & $38(X w P t-1708)$ & 14.3 & 37-39 (Xwmc48.2-XwPt1708) & 26.0 & -2.0 \\
\hline & & 4DS & $28(R h t-D 1)$ & 4.4 & 21-34 (Rht-D1-Xgpw94042) & 7.1 & 1.1 \\
\hline & PU08 & $6 \mathrm{AL}$ & $60(X w P t-5094)$ & 6.0 & 57-62 (Xbarc3-XwPt-5094) & 12.0 & 1.2 \\
\hline & & 1BS & $0(R I S)$ & 3.3 & $0-2(R I S-X b a r c 240)$ & 5.5 & -0.8 \\
\hline & & $2 \mathrm{BL}$ & 99 (Xbarc1155) & 4.3 & 86-103 (Xbarc1155-Xgwm388) & 8.8 & 1.0 \\
\hline & & 4BS & $32(R h t-B 1)$ & 11.8 & 31-33 (Rht-B1-Xwmc48.2) & 24.7 & -1.8 \\
\hline & & 4DS & $28(R h t-D 1)$ & 4.2 & 22-31 (Rht-D1-Xgpw94042) & 7.7 & 1.0 \\
\hline & MC08 & $6 \mathrm{AL}$ & $62(X w m c 32)$ & 4.7 & 59-66 (XwPt-5094-Xbarc107) & 10.7 & 1.2 \\
\hline & & 7AL & $15(X w m c 273)$ & 3.6 & 10-21 (Xgwm146-Xwmc273) & 7.9 & 1.1 \\
\hline & & $4 \mathrm{BL}$ & $44($ Xgwm192) & 4.5 & 43-46 (Xgwm192-Xgwm149) & 10.3 & -1.2 \\
\hline & $\mathrm{CB}$ & $6 \mathrm{AL}$ & $61(X w m c 32)$ & 5.5 & 59-66 (XwPt-5094-Xwmc32) & 10.2 & 1.0 \\
\hline & & 7AL & $15(X w m c 273)$ & 3.1 & 9-20 (Xgwm146-Xwmc273) & 5.3 & 0.7 \\
\hline & & $2 \mathrm{BL}$ & $93($ Xbarc 1155) & 4.3 & 83-104 (Xbarc1155-Xgwm388) & 7.7 & 0.9 \\
\hline & & 4BL & $41($ Xgwm495) & 9.9 & 40-43 (Xgwm513-Xgwm192) & 18.5 & -1.3 \\
\hline
\end{tabular}

CR07 Corvallis (OR), 2007; CR08 Corvallis (OR), 2008; MR08 Moro (OR), 2008; PE08 Pendleton (OR), 2008; PU08 Pullman (WA), 2008; $M C 08$ Moscow (ID), 2008; $C B$ Combined across field environments

a The letter $\mathrm{S}$ represented the short arm of chromosome, and $\mathrm{L}$ indicated the long arm of chromosome

${ }^{b}$ Position of QTL peak is expressed in centiMorgans (cM), nearest locus to QTL peak is indicated in brackets

${ }^{c}$ Logarithm of the odds ratio (LOD) of QTL peak that exceeded the significant LOD threshold from 1,000 permutations

${ }^{\mathrm{d}}$ The flanking loci of 1-LOD support limit are indicated in brackets

e $R^{2}$ is the proportion of the phenotypic variance explained by the QTL after accounting for co-factors

${ }^{\mathrm{f}}$ Positive additive values indicate that higher value alleles are from Stephens (OS9A) and the negative values indicate that the higher value alleles are from OR9900553 (QCB36) 
Thousand-kernel weight (TKW) QTL

A total of nine QTL were detected on chromosomes 6AL, 7AL, 1BS, 2BL, 4BS, 4BL, 3DL, and 4DS (Table 2; Fig. 1). The major QTL, Qtkw.orr-6A, mapped to the interval between XwPt-5094 and Xwmc3, was detected in six environments, and detected across environments. Qtkw.orr-4B on chromosome 4BL explained $10.3-18.5 \%$ of the phenotypic variance with negative additive effects ranging between 1.2 and 1.5. Qtkw.orr- $2 B$ was mapped to the interval between Xbarc1155 and Xgwm388, explaining 7.7-9.3\% of the phenotypic variance. Qtkw.orr-7A and Qtkw.orr-3D were detected only at PE08 and CR08, and accounted for 5.4 and $6.9 \%$ of the phenotypic variance, respectively. Parent OS9A contributed high-value alleles at all identified QTL except the QTL on chromosome 4B.

Effects of semi-dwarfing genes on kernel hardness

Due to the identification of major QTL for most traits near semi-dwarfing genes Rht-Dl and Rht-Bl, the possible effects of $R h t$ alleles on variation in grain hardness were analyzed. RILs of the OS9 $\times$ Q36 population were classified as semi-dwarf (carried the semi-dwarf allele Rht-B1b or Rht-Dlb), dwarf (carried both semi-dwarf alleles Rht$B 1 b$ and $R h t-D 1 b$ ), or tall (carried both tall alleles Rht-Bla and $R h t-D l a$ ) (Fig. 2). Even though the four combinations of $R h t$ alleles produced three distinct groups of RILs based on PHT, no significant correlation was observed between hardness and PHT among RILs. This was due to the fact that lines with semi-dwarf allele Rht-B1b had higher kernel hardness, whereas lines with semi-dwarf allele Rht-Dlb had lower kernel hardness. This association is presumably due to linkage of $R h t$ alleles and QTL alleles decreasing hardness or pleiotropic effects of Rht alleles, as confirmed by pairwise t-tests on hardness of the four genotypic groups classified based on alleles at Rht-Bl and Rht-Dl among individuals of the RIL population. The genotypic class of 36 RILs with tall allele Rht-Bla and semi-dwarf allele $R h t$ $D 1 b$ had a mean hardness index of 18.0 , significantly $(P<0.005)$ lower than that of the other three genotypic classes with mean hardness indexes of 23.3, 23.5, and 25.5.

\section{Discussion}

QTL for hardness and milling yield

Most QTL detected for the nine traits investigated in this study were localized to similar genomic regions identified in previous studies. As expected, two major QTL for PHT, representing the effect of the well-known semi-dwarfing genes Rht-Bl and Rht-Dl on chromosomes 4BS and 4DS,

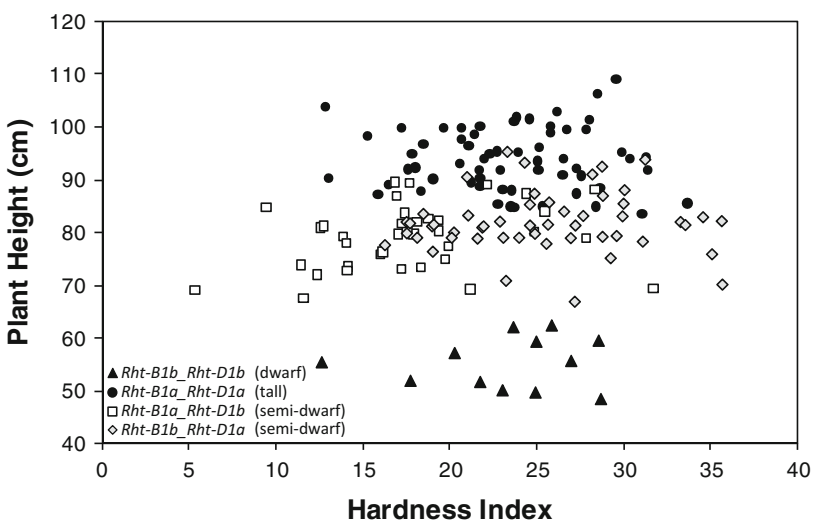

Fig. 2 Relationship between kernel hardness and plant height in the two parent and the mapping population of 164-recombinant inbred lines (RILs) developed from the cross between OS9A (soft, Rht-B1b Rht-D1a) and QCB36 (extra-soft, Rht-B1a Rht-D1b). Symbols indicate allele status at the two Rht loci

respectively, were identified (Börner et al. 1997; Ellis et al. 2002). Another minor QTL, Qpht.orr-6A, coincides with a previously reported QTL (Spielmeyer et al. 2007). Our study is consistent with other studies where the variation for PHT is largely explained by the effect of $R h t$ genes but also under polygenic control. All three QTL were consistently detected in different environments. The consistent detection of identical QTL from trial to trial suggests little $\mathrm{G} \times \mathrm{E}$ interaction.

Previous studies identified the $\mathrm{Ha}$ locus and puroindoline genes on 5DS as the major genetic determinants controlling variation between hard and soft wheat. The continuous distribution for kernel hardness in the OS9 $\times$ Q36 population is different from the bimodal distribution typically seen in RIL populations developed from soft $\times$ hard wheat crosses (Bergman et al. 1998; Campbell et al. 1999). By eliminating variation at $\mathrm{Ha}$ locus in the choice of our parental lines, we were able to focus on other loci that influence and determine the difference between soft and 'extra-soft' grain hardness. Thus, we were able to identify two major QTL on chromosomes 4BS (Qkha.orr$4 B$ ) and 4DS (Qkha.orr-4D) close to the semi-dwarfing genes $R h t-B 1$ and $R h t-D 1$ that explained up to 20 and $34 \%$ of the phenotypic variance for kernel hardness, respectively. The QTL on chromosome 4DS is most likely identical to a previously reported QTL location for grain hardness (Li et al. 2009; Zanetti et al. 2001). However, to our knowledge, this is the first report of a major QTL for hardness on chromosome 4BS. Additionally, two QTL with minor effects on hardness were found on chromosomes 5DL and 7DS. Therefore, this QTL analysis revealed that inheritance of the soft kernel characteristic is complex. Based on map comparisons, the QTL on chromosomes 4BS and 4DS (Qkha.orr-4B and Qkha.orr-4D) appear to be orthologous loci. 
Several genetic factors are probably involved in the determination of grain hardness and the three milling yield traits in our study. Two coincident QTL were found on chromosomes 4DS and 5BS for BFY, BRN, and MID, even though the effect of the QTL on chromosome 4DS for BFY is much smaller than the effect on hardness. Similarly, the QTL mapped to chromosome 4BS for BFY and BRN, was also coupled with a QTL for KHA, but its effect on these two traits was less than that for hardness. Another co-located QTL for BFY and BRN, which explained up to $15 \%$ of the phenotypic variance, was associated with the 1BL.1RS chromosome translocation. The identification of this QTL is consistent with the observation that the 1BL.1RS translocation can affect grain characteristics and may be associated directly with other endosperm characteristics rather than hardness per se (Kim et al. 2004). Three other QTL detected in this study, Qbfy.orr- $4 B$, Qbfy.orr-2D, and Qbfy.orr-4D, were in agreement with previously reported QTL for flour yield of hard wheat (Christopher 2008; McCartney et al., 2006; Schmidt 2004). None of the QTL associated with BRN and MID flour yield have been previously reported. The significant QTL on chromosomes 4BS and 4DS coincided with hardness, indicating that there exist two potential QTL accounting for most variation of kernel hardness. Of interest is to understand the relationship between these two coincident QTL for KHA, BFY, BRN, and MID, and semi-dwarfing genes $R h t-B 1$ and $R h t-D 1$, respectively, that are in their vicinity.

\section{QTL for agronomic traits}

Three QTL identified for HDD in this study were coincident with QTL identified in previous studies. However, we were unable to identify any significant QTL near the vernalization gene $V r n-B 1$ on chromosome 5B despite variation for HDD among RILs of this population. Our inability to detect the influence of $V r n-B I$ alleles may be due to complete vernalization of materials in the field and confounding effects of other factors that affect flowering time, including alleles at the earliness per se loci. The minor QTL we identified on chromosome 7DS for HDD may be identical to a QTL identified in previous studies (Borner et al. 2002; Sourdille et al. 2000). Qhdd.orr-4D and Qhdd.orr-6B were reported to be associated with earliness per se (Hoogendoorn 1985), suggesting that our population is segregating for alleles at these loci. The QTL on chromosome 4DS coincident with hardness suggests that HDD or factors affecting HDD may influence kernel hardness or endosperm texture through a pleiotropic effect.

Six out of nine TKW QTL reported here had not been reported elsewhere. However, three QTL, one each on chromosome 6A (Qtkw.orr-6A between markers Xbarc3 and Xbarc107), 1B [Qtkw.orr-1B near marker RIS
(1RS.1BL)] and 2B (Qtkw.orr-2B near Xgwm388) were in agreement with QTL identified previously (Groos et al. 2003; Huang et al. 2004; Snape et al. 2007). As for TWT QTL, the QTL on chromosome 2DL was consistent with a previously identified QTL as well (Narasimhamoorthy et al. 2006). Taking into consideration the influence of HDD on grain filling, some concurrent genetic factors for HDD, TKW, and TWT may exist. Therefore, it is not surprising that coincident QTL on chromosome 4DS were mapped for HDD, TKW, and TWT in the present study.

Two of six GPC QTL identified in this study appeared similar to those reported previously in wheat. Qgpc.orr-6B between markers Xbarc101 and Xbarc103, and Qgpc.orr$2 A$ between markers Xcmwg682 and Xcfd36 occupied similar chromosome regions to QTL identified elsewhere (Groos et al. 2003; Joppa et al. 1997; Khan et al. 2000). However, four minor GPC QTL on chromosomes 1AL, 3BL, 5DL, and 7DL were identified only in this study. All QTL for GPC could only be detected in a single environment except Qgpc.orr-7D, and no significant QTL was detected at PE08 or PU08. It seems that the limited phenotypic variation for this trait in the mapping population is the primary reason for our inability to detect QTL for GPC across environments.

\section{Co-location of QTL}

We observed a total of seven coincident QTL for at least two different traits on chromosomes $1 \mathrm{~B}, 4 \mathrm{~B}, 5 \mathrm{~B}, 4 \mathrm{D}, 5 \mathrm{D}$, $6 \mathrm{~A}$, and 7A. Of these, the most significant QTL for eight out of the nine investigated traits was mapped to the same chromosome region near semi-dwarfing gene Rht-Dl on chromosome 4DS. GPC was the only trait investigated that lacked QTL in this chromosomal region. Similarly, another coincident QTL for six investigated traits was detected on the chromosomal region near Rht-Bl on chromosome 4BS. These findings are generally consistent with the QTL identified in other studies in which both semi-dwarfing genes Rht-Bl and Rht-Dl have been reported to be associated with some agronomic traits and disease resistance including TWT, TKW, and Fusarium crown rot (Collard et al. 2005; McCartney et al. 2006; Singh et al. 2001; Wallwork et al. 2004). Besides these, Qbfy.orr-5B was coincident with QTL for MID and BRN on chromosome 5B. Coincident QTL for three traits (BFY, BRN, and TKW) were detected in the same marker interval $R I S$ Xbarc 240 on chromosome 1BS (representing the chromosome translocation 1BL.1RS) that has been reported previously (Moreno-Sevilla et al. 1995). Both Qbrn.orr-6B, and Qmid.orr-6B were coincident with QTL for HDD on chromosome 6BL. A QTL for BRN was located on the same region of chromosome 3B as a QTL for GPC. These coincident QTL for multiple traits were consistent across 
environments, suggesting that these traits may be correlated with each other and may share common genetic factors. If this is the case, all traits measured in this study except GPC are correlated with KHA. This correlation has two possible explanations. One interpretation is pleiotropic effects of single genes. Alternatively, multiple closely linked genes cannot be ruled out in a QTL study due to limits in mapping resolution. Although our analysis suggests the former, we cannot conclusively distinguish between these two possible explanations for QTL coincidence.

Selection of soft wheat cultivars with high flour yield and superior end-use quality has been successful because of the important negative correlation between milling flour yield and KHA. However, until now, the genetic control of the 'extra-soft' characteristic has not received much attention. This may reflect the fact that texture variation from soft to 'extra-soft' is small relative to the much larger difference between soft and hard wheat. In addition, the large effect of the $\mathrm{Ha}$ locus is more amenable to qualitative genetic studies. The quantitative nature of the genetic determinants of the 'extra soft' trait and smaller phenotypic effects of these loci make the objectives of this study more challenging. Nonetheless, we have been able to show that at least five QTL directly contribute to the 'extra-soft' characteristic.

\section{Relationship of Rht genes and kernel hardness}

Our study suggested that KHA is not influenced directly by $R h t$ genes, even though we found an association of both $R h t-B 1$ and $R h t-D 1$ genes with kernel hardness. Also, there is probably no pleiotropic effect of the dwarfing gene Rht$B 1$ based on analysis of lines carrying different alleles of $R h t-D 1$ and Rht-B1. Path coefficient analysis supported the contention that KHA and BFY are not highly associated with PHT (Richards 1992). In contrast, both KHA and BFY were observed to be highly correlated with other agronomic traits, such as HDD and TWT in our study. Recent studies have revealed that GPC is positively correlated with KHA. This is supported by studies where softer wheat grain had lower protein content than hard wheat (Gaines 1985; Nelson et al. 2006; Yamazaki and Donelson 1983).

This study identified 11 QTL for wheat KHA and BFY, along with significant QTL for other agronomic traits, thus increasing our understanding of the underlying genetic factors controlling kernel hardness, break flour yield, and other agronomic traits. The QTL reported here could orient marker-assisted selection strategies to breed for high market value 'extra-soft' wheat lines. The identification of significant QTL is also the first step in identifying the specific genetic factors that underline phenotypes of interest. In this case, we have identified two QTL that contribute to the 'extra-soft' phenotype. Fine mapping of these QTL near Rht genes would be the next step towards isolating and identifying the relevant genes.

Acknowledgments We would like to thank Dr. C. F. Morris for providing access to the milling facilities at the USDA-ARS Western Wheat Quality Lab (Pullman, WA). Financial support from the National Research Initiative of the USDA-Coordinate State Research, Education and Extension Service (Coordinate Agricultural Project (CAP) grant number 2006-55606-16629), Oregon State University Agricultural Research Foundation, Oregon Agricultural Experiment Station, and the Oregon Wheat Commission, is greatly appreciated (All the above grants were awarded to Dr. Oscar Riera-Lizarazu while he was a faculty at Oregon State University).

\section{References}

Beecher B, Bettge A, Smidansky E, Giroux M (2002) Expression of wild-type pinB sequence in transgenic wheat complements a hard phenotype. Theor Appl Genet 105:870-877

Bergman CJ, Gualberto DG, Campbell KG, Sorrells ME, Finney PL (1998) Genotype and environment effects on wheat quality traits in a population derived from a soft by hard cross. Cereal Chem 75:729-737

Borner A, Schumann E, Furste A, Coster H, Leithold B, Roder MS, Weber WE (2002) Mapping of quantitative trait loci determining agronomic important characters in hexaploid wheat (Triticum aestivum L.). Theor Appl Genet 105:921-936

Börner A, Röder M, Korzun V (1997) Comparative molecular mapping of GA insensitive Rht loci on chromosomes 4B and 4D of common wheat (Triticum aestivum L.). Theor Appl Genet 95:1133-1137

Breseghello F, Finney PL, Gaines C, Andrews L, Tanaka J, Penner G, Sorrells ME (2005) Genetic loci related to kernel quality differences between a soft and a hard wheat cultivar. Crop Sci 45:1685-1695

Campbell KG, Bergman CJ, Gualberto DG, Anderson JA, Giroux MJ, Hareland G, Fulcher RG, Sorrells ME, Finney PL (1999) Quantitative trait loci associated with kernel traits in a soft $x$ hard wheat cross. Crop Sci 39:1184-1195

Chen XM, Line RF (1995) Gene action in wheat cultivars for durable, high-temperature, adult-plant resistance and interaction with race-specific, seedling resistance to Puccinia striiformis. Phytopathology 85:567-572

Christopher MJ, Butler D, Rodgers D, Mace ES, Martin D, McGowan P, Jordan D, Shatte T, Jennings R, DeLacy I (2008) Flour yield and water absorption in wheat-a pedigree mapping approach. In: Appels R et al (ed) Sydney University Press

Collard BCY, Grams RA, Bovill WD, Percy CD, Jolley R, Lehmensiek A, Wildermuth G, Sutherland MW (2005) Development of molecular markers for crown rot resistance in wheat: mapping of QTLs for seedling resistance in a ' $2-49^{\prime} \times$ 'Janz' population. Plant Breed 124:532-537

Ellis MH, Spielmeyer W, Gale KR, Rebetzke GJ, Richards RA (2002) "Perfect" markers for the Rht-B1b and Rht-D1b dwarfing genes in wheat. Theor Appl Genet 105:1038-1042

Fu D, Szucs P, Yan L, Helguera M, Skinner JS, von Zitzewitz J, Hayes PM, Dubcovsky J (2005) Large deletions within the first intron in VRN-1 are associated with spring growth habit in barley and wheat. Mol Genet Genomics 273:54-65

Gaines CS (1985) Associations among soft wheat flour particle size, protein content, chlorine response, kernel hardness, milling 
quality, white layer cake volume, and sugar-snap cookie spread. Cereal Chem 62:290-292

Giroux MJ, Morris CF (1998) Wheat grain hardness results from highly conserved mutations in the friabilin components puroindoline $a$ and b. Proc Natl Acad Sci USA 95:6262-6266

Greenwell P, Schofield JD (1986) A starch granule protein associated with endosperm softness in wheat. Cereal Chem 63:379-380

Groos C, Robert N, Bervas E, Charmet G (2003) Genetic analysis of grain protein-content, grain yield and thousand-kernel weight in bread wheat. Theor Appl Genet 106:1032-1040

Hogg AC, Sripo T, Beecher B, Martin JM, Giroux MJ (2004) Wheat puroindolines interact to form friabilin and control wheat grain hardness. Theor Appl Genet 108:1089-1097

Hoogendoorn J (1985) A reciprocal F1 analysis of the genetic control of the time of ear emergence, number of leaves and number of spikelets in wheat (Triticum aestivum L.). Euphytica 34:545-558

Huang XQ, Kempf H, Ganal MW, Röder MS (2004) Advanced backcross QTL analysis in progenies derived from a cross between a German elite winter wheat variety and a synthetic wheat (Triticum aestivum L.). Theor Appl Genet 109:933-943

Jolly CJ, Glenn GM, Rahman S (1996) GSP-1 genes are linked to the grain hardness locus $(\mathrm{Ha})$ on wheat chromosome 5D. Proc Natl Acad Sci USA 93:2408-2413

Joppa LR, Du C, Hart GE, Hareland GA (1997) Mapping gene(s) for grain protein in tetraploid wheat (Triticum turgidum L.) using a population of recombinant inbred chromosome lines. Crop Sci 37:1586-1589

Khan IA, Procunier JD, Humphreys DG, Tranquilli G, Schlatter AR, Marcucci-Poltri S, Frohberg RC, Dubcovsky J (2000) Development of PCR-based markers for a high grain protein content gene from Triticum turgidum ssp. dicoccoides transferred to bread wheat. Crop Sci 40:518-524

Kim W, Johnson J, Baenziger P, Lukaszewski A, Gaines C (2004) Agronomic effect of wheat-rye translocation carrying rye chromatin (1R) from different sources. Crop Sci 44:1254-1258

Li Y, Song Y, Zhou R, Branlard G, Jia J (2009) Detection of QTLs for bread-making quality in wheat using a recombinant inbred line population. Plant Breed 128:235-243

Mattern PJ, Morris R, Schmidt JW, Johnson VA (1973) Location of genes for kernel properties in the wheat variety 'Cheyenne' using chromosome substitution lines. In: Proceedings of the 4th International Wheat Genetics Symposium, Columbia, pp 703-708

McCartney CA, Somers DJ, Lukow O, Ames N, Noll J, Cloutier S, Humphreys DG, McCallum BD (2006) QTL analysis of quality traits in the spring wheat cross RL4452 $\times$ 'AC Domain'. Plant Breed 125:565-575

Moreno-Sevilla B, Baenziger PS, Peterson CJ, Graybosch RA, McVey DV (1995) The 1BL/1RS translocation: agronomic performance of F3-derived lines from a winter wheat cross. Crop Sci 35:1051-1055

Narasimhamoorthy B, Gill BS, Fritz AK, Nelson JC, Brown-Guedira GL (2006) Advanced backcross QTL analysis of a hard winter wheat $\times$ synthetic wheat population. Theor Appl Genet 112:787-796

Nelson JC, Andreescu C, Breseghello F, Finney PL, Gualberto DG, Bergman CJ, Peña RJ, Perretant MR, Leroy P, Qualset CO
(2006) Quantitative trait locus analysis of wheat quality traits. Euphytica 149:145-159

Parker GD, Chalmers KJ, Rathjen AJ, Langridge P (1999) Mapping loci associated with milling yield in wheat (Triticum aestivum L.). Mol Breed 5:561-568

Richards RA (1992) The effect of dwarfing genes in spring wheat in dry environments. I. Agronomic characteristics. Aust J Agric Res 43:517-527

Riera-Lizarazu O, Peterson CJ, Wang G, Leonard JM (2010) Registration of the OS9 $\times$ Q36 mapping population of wheat (Triticum aestivum L.). J Plant Regist 4:98-104

Schmidt AL, Liu CJ, Martin D, Kelly A, McIntyre L (2004) Molecular markers for selected quality traits in Australian hexaploid bread wheat. In: Proceedings of the 4th International Crop Science Congress, Brisbane

Singh RP, Huerta-Espino J, Rajaram S, Crossa J (2001) Grain yield and other traits of tall and dwarf isolines of modern bread and durum wheats. Euphytica 119:241-244

Snape JW, Foulkes MJ, Simmonds J, Leverington M, Fish LJ, Wang Y, Ciavarrella M (2007) Dissecting gene $\times$ environmental effects on wheat yields via QTL and physiological analysis. Euphytica 154:401-408

Somers DJ, Isaac P, Edwards K (2004) A high-density microsatellite consensus map for bread wheat (Triticum aestivum L.). Theor Appl Genet 109:1105-1114

Sourdille P, Perretant MR, Charmet G, Leroy P, Gautier MF, Joudrier P, Nelson JC, Sorrells ME, Bernard M (1996) Linkage between RFLP markers and genes affecting kernel hardness in wheat. Theor Appl Genet 93:580-586

Sourdille P, Snape JW, Cadalen T, Charmet G, Nakata N, Bernard S, Bernard M (2000) Detection of QTLs for heading time and photoperiod response in wheat using a doubled-haploid population. Genome 43:487-494

Spielmeyer W, Hyles J, Joaquim P, Azanza F, Bonnett D, Ellis ME, Moore C, Richards RA (2007) A QTL on chromosome 6A in bread wheat (Triticum aestivum) is associated with longer coleoptiles, greater seedling vigour and final plant height. Theor Appl Genet 115:59-66

Van Ooijen JW (2004) MapQTL ${ }^{\circledR}$ 5, Software for the mapping of quantitative trait loci in experimental populations. Kyazma BV, Wageningen

Van Ooijen JW (2006) JoinMap 4.0, Software for the calculation of genetic linkage maps in experimental populations. Wageningen

Voorrips RE (2002) MapChart: software for the graphical presentation of linkage maps and QTLs. J Hered 93:77-78

Wallwork H, Butt M, Cheong JPE, Williams KJ (2004) Resistance to crown rot in wheat identified through an improved method for screening adult plants. Aust Plant Pathol 33:1-7

Yamazaki WT, Donelson JR (1983) Kernel hardness of some US wheats. Cereal Chem 60:344-350

Zanetti S, Winzeler M, Feuillet C, Keller B, Messmer M (2001) Genetic analysis of bread-making quality in wheat and spelt. Plant Breed 120:13-19 